\title{
ANÁLISE DAS PROPRIEDADES MECÂNICAS E MICROESTRUTURAIS DO AÇO INOX DUPLEX SUBMETIDO A PROCESSOS DE SOLDAGEM
}

\author{
ANALYSIS OF THE MECHANICAL AND MICROSTRUCTURAL PROPERTIES OF \\ DUPLEX STAINLESS STEEL WHEN SUBMITTED AT DIFERENT WELDING \\ PROCESSES
}

\author{
Simoni Maria Gheno ${ }^{\mathrm{I}}$ \\ Felipe do Nascimento Gonçalves II \\ Jeferson de Oliveira ${ }^{\text {III }}$ \\ Maria Aparecida Bovério IV
}

\begin{abstract}
RESUMO
A ampla utilização do aço inoxidável duplex se deve especialmente a combinação de excelentes propriedades mecânicas e alta resistência à corrosão. Nesse trabalho estudou-se as propriedades mecânicas e as fases microestruturais do aço inoxidável duplex após os processos de soldagem: eletrodo revestido (SMAW), Metal Inert Gás (MIG) e Tungstênio Inert Gás (TIG). Em seguida ao processo de soldagem, o material era submetido ao tratamento térmico a uma temperatura de $475{ }^{\circ} \mathrm{C}$. As microestruturas foram analisadas com ataque Behara, para verificação de precipitação nas temperaturas próximas de $475{ }^{0} \mathrm{C}$ e posteriormente realizado o ensaio de microdureza Vickers. Observou-se um pequeno aumento de dureza nos corpos de prova especificamente na região de soldagem, porém observou-se também a presença da precipitação da fase $\alpha$ '. Em relação aos processos de soldagem adotados, eles mostraram que ao longo do processo, a estrutura do material apresentou o defeito de falta de fusão que foi mais bem caracterizado após análise de microscopia óptica feita com o objetivo de quantificar e verificar os defeitos apresentados nas amostras. Todas as amostras analisadas apresentaram o defeito de falta de fusão, apesar da falta de penetração obtida em todas as amostras. Em todas elas fica evidente a ausência de trincas, mordeduras e sobreposição, mostrando que todos os processos podem ser eficazes no aço inox duplex.
\end{abstract}

Palavras-chave: Aço Inoxidável. Soldagem. Caracterização.

\begin{abstract}
The wide use of duplex stainless steel is especially due to the combination of excellent mechanical properties and high corrosion resistance. In this work we studied the mechanical properties and microstructural phases of duplex stainless steel after welding processes: Coated electrode (SMAW), Metal Inert gas (MIG) and tungsten Inert gas (TIG). After the welding process, the material was subjected to heat treatment at a temperature of $475^{0} \mathrm{C}$. The

I Profa. Pós-Dra. da Faculdade de Tecnologia (FATEC) de Sertãozinho - SP - Brasil. E-mail: simoni.gheno@cps.sp.gov.br

II Prof. Coord. da Escola Técnica Estadual de Furnas - MG - Brasil E-mail: felipenascimento789@ hotmail.com

III Prof. Dr. da Universidade Paulista (UNIP) de Ribeirão Preto - SP - Brasil. E-mail: jeferson.oliveira@docente.unip.br

Iv Profa. Pós-Dra. da Faculdade de Tecnologia (FATEC) de Sertãozinho - SP - Brasil. E-mail: mariaboverio@ hotmail.com
\end{abstract}




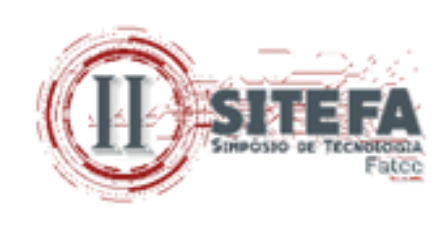

microstructures were analyzed with Behara attack, to check for precipitation at temperatures close to $475^{\circ} \mathrm{C}$ and subsequently performed the Vickers microhardness assay. There was a small increase of hardness in the specimens specifically in the welding region, but the presence of the precipitation of the $\alpha$ phase was also observed. In relation to the welding processes adopted, they showed that throughout the process, the structure of the material presented the defect of lack of fusion that was best characterized after optical microscopy analysis made with the objective of quantifying and verifying the Defects presented in the samples. All the samples analyzed presented the defect of lack of fusion, despite the lack of penetration obtained in all samples. In all of them it is evident the absence of cracks, bites and overlap, showing that all processes can be effective in duplex stainless steel.

Keywords: Stainless Steel. Welding. Characterization.

Data de submissão do artigo: 18/06/2019.

Data de aprovação do artigo: 01/10/2019.

DOI:

\section{INTRODUÇÃO}

As jazidas de petróleo em território nacional sobretudo as da camada pré-sal vêm colocando em discussão quais os métodos e as tecnologias mais eficientes para explorá-las. Neste âmbito, existe inúmeros equipamentos e máquinas industriais que são submetidos a ambientes agressivos e condições severas de trabalho, o que gera um desgaste excessivo de componentes e, consequentemente, muitas manutenções. Adicionalmente, também há o setor de produção sucroalcooleira (açúcar, álcool e energia) que necessita de inovação tecnológica e pesquisa aplicada para atender ao crescimento exponencial do setor nos últimos anos, bem como aos requisitos técnicos para a exportação dos produtos. Desta forma, o desenvolvimento tecnológico exige demanda cada vez maior de processos tecnológicos que solucionem os problemas reais. Nessa categoria de aplicação de materiais estão os aços inoxidáveis dúplex (AID) (ABINOX, 2016).

Os aços inoxidáveis duplex (AID) foram desenvolvidos no ano de 1927 e se tornaram comercialmente disponíveis na produção industrial e pesquisa realizada na Suécia, França e Estados Unidos (NILSSON, 1992; MATEO et al., 2001). Desde então, estas ligas têm sofrido inúmeras modificações que vão desde a sua composição, até as tecnologias usadas na sua produção. Os AID modernos possuem uma excelente resistência a corrosão e boas propriedades mecânicas, combinação que tem impulsionado o seu uso, cada vez mais, em ambientes altamente agressivos. São geralmente processados através do sistema da técnica de descaburação por sopro combinado de oxigênio e argônio (AOD) que faz com que o aço apresente baixo teor de carbono (SEDRIKS, 1996).

O AID é uma liga formada por cerca de $18 \%$ a $30 \%$ de Cr, $1,5 \%$ a $4,5 \%$ de Mo mais elementos formadores e estabilizantes da austenita, essencialmente o níquel e o nitrogênio, de modo a formar uma microestrutura composta de partes aproximadamente iguais de ferrita e austenita, quando em temperatura ambiente. Estes aços são magnéticos e a estrutura ferrítica conferem-lhes uma elevada resistência a corrosão enquanto a estrutura austenítica proporciona elevada resistência mecânica e boa soldabilidade (LIMA, 2006). 


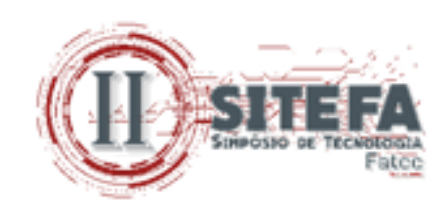

Os AIDs são ligas fundamentadas no sistema Fe-Cr-Ní-Mo-N na faixa de composição: $18,5 \%$ a $27 \%$ de $\mathrm{Cr} ; 4 \%$ a $8 \%$ de Ni; $2 \%$ a $4 \%$ Mo; C menor do que $0,08 \%$ e, também, podem conter $\mathrm{Cu}$. A sua microestrutura bifásica ferrita-austenita é determinada principalmente pelos teores de $\mathrm{Fe}, \mathrm{Cr}$ e Ni (SEDRIKS, 1996). Esse aço é muito influenciado pela velocidade de resfriamento e do tempo de manutenção da temperatura, podendo, assim, obter outras fases a não ser a ferrita e austenita, ocasionando a fragilização destes aços. As temperaturas que fragilizam esse aço podem ser divididas em duas faixas: fragilização a baixa temperatura, na qual ocorre em uma faixa de temperatura de $300^{\circ} \mathrm{C}$ a $500^{\circ} \mathrm{C}$, e fragilização a alta temperatura, na qual ocorre em uma faixa de temperatura de $600^{\circ} \mathrm{C}$ a $1000^{\circ} \mathrm{C}$ (NILSON, 1992; WELLS, 1952; CHARLES, 1997).

Nos AIDs a resistência a corrosão é semelhante aos aços inoxidáveis austeníticos, no entanto com melhores propriedades mecânicas. As propriedades de resistência a corrosão são melhoradas devido a menor presença de níquel, tornando-os mais moderados a crescente tendência de aços mais ligados com nitrogênio, estabilizando assim a fase austenítica e diminuindo a partição do cromo na ferrita (LIMA, 2006).

Uma particularidade dos AID que merece cuidados é o fator precipitação. Ao submeter os AIDs a uma temperatura de $425^{\circ} \mathrm{C}$ a $525^{\circ} \mathrm{C}$, acontece a formação da fase $\alpha$ ' por meio da decomposição espinodal. A transformação é mais rápida a temperatura de $475^{\circ} \mathrm{C}$ (ALBUQUERQUE et al., 2010). A fase $\alpha^{\prime}$ rica em cromo e a fase $\alpha$ rica em ferro podem ser verificadas após o envelhecimento da ferrita a temperaturas abaixo de $475^{\circ} \mathrm{C}$ (MAGNABOSCO, 2004). A presença da fase $\alpha^{\prime}$ em forma de partículas muito pequenas disseminadas na ferrita original causa endurecimento nos AIDs. Portanto o surgimento da fase $\alpha$ ' é comprovado pelo acréscimo de dureza e consequentemente pelo decréscimo da tenacidade com o aumento dos tempos de envelhecimento a temperatura de $475^{\circ}$ (SOLOMON; DEVINE JUNIOR, 1982; 1984). Depois de grandes períodos em temperaturas baixas, cerca de $300^{\circ} \mathrm{C}$ a fase $\alpha^{\prime}$ também pode ser verificada (SANTOS, 2008).

\section{PROCESSOS DE SOLDAGEM}

A soldagem envolve muitos fenômenos metalúrgicos como, por exemplo, fusão, solidificação, transformações no estado sólido, deformações causadas pelo calor e tensões de contração, que podem causar muitos problemas práticos (WAINER; BRANDI; MELLO, 1982; MARQUES; MODENESI; BRACARENSE, 2005).

Um fenômeno que pode acontecer no processo de soldagem é a repartição térmica que ocorre onde a temperatura varia desde a zona de fusão até o metal base, mais especificamente nos ciclos térmicos de soldagem. Os efeitos dos ciclos térmicos de soldagem podem dificultar que as fases austenita e ferrita presentes nos AIDs sejam mantidas após o processo de soldagem. Na soldagem de AID, a microestrutura varia desde a poça de fusão até o metal base e a microestrutura final depende da velocidade de resfriamento a partir de cada temperatura máxima presente na repartição térmica. Diversos fatores podem influenciar as propriedades da solda, são eles: a composição química, o procedimento, o processo de soldagem e o balanço entre a austenita e a ferrita presentes na microestrutura. Alterações na composição química e o controle da temperatura durante a soldagem podem ajustar o balanço entre a austenita e a ferrita (LIMA, 2006).

A escolha do processo de soldagem envolve basicamente quatro fatores: projeto da junta, espessura do material, natureza do material a ser soldado e o custo de fabricação (WAINER; BRANDI; MELLO, 1982; MARQUES; MODENESI; BRACARENSE, 2005). 


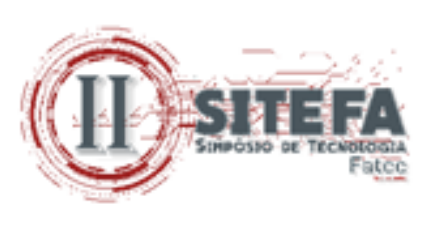

Entre os vários processos de soldagem existentes o mais amplamente utilizado é a soldagem a arco elétrico com eletrodo revestido, o Shielded Metal Arc Welding (SMAW). O calor produzido pelo arco funde a alma do eletrodo, o revestimento e o metal base. Através do arco as gotas de metal fundido são transferidas para a poça de fusão, os gases produzidos durante a decomposição do revestimento as protegem da atmosfera.

Na soldagem a arco elétrico com gás de proteção, o Gas Metal Arc Welding (GMAW), também conhecida como soldagem Metal Inert Gas (MIG) e Metal Active Gas (MAG) - MIG/ MAG, o arco funde de maneira ininterrupta o arame à medida que este é alimentado à poça de fusão. A ação protetora contra a atmosfera é realizada pelo fluxo de um gás inerte (argônio ou hélio), ativo (dióxido de carbono) ou a mistura dos dois.

O processo de soldagem TIG - Gas Tungsten Arc Welding (GTAW) é um processo de soldagem que utiliza um arco elétrico entre um eletrodo não consumível de tungstênio e a poça de soldagem (BRACARENSE, 2000).

A produção da maioria de equipamentos e máquinas utilizados tanto na indústria petroquímica quanto na sucroalcooleira e de energia envolve o uso de processos de soldagem e, durante o processo de soldagem a junta soldada experimenta diferentes valores de temperatura e tempos de resfriamento, o que pode afetar as características microestruturais tanto do cordão de solda quanto do metal-base. Sendo assim, é necessário conhecer como os processos de soldagem influenciam o comportamento da junta soldada, quais processos são mais adequados.

Nesse sentido, o objetivo deste estudo foi investigar as propriedades mecânicas e microestruturais do aço inoxidável duplex, submetido aos processos de soldagem: Arco Elétrico com Eletrodo Revestido, MIG/MAG e TIG. Para alcançar esse objetivo, neste trabalho verificou-se os seguintes parâmetros: (i) análise química do material base, (ii) identificação através das microestruturas possíveis falhas e defeitos obtidos nos processos de soldagem, (iii) influência do processo de soldagem na dureza, (iv) Influência do tratamento térmico de precipitação por envelhecimento no cordão de solda e no material base.

\section{PROCEDIMENTOS METODOLÓGICOS}

Os procedimentos metodológicos adotados para esta pesquisa foram: pesquisa bibliográfica, documental, laboratorial e aplicada. A pesquisa bibliográfica foi elaborada a partir de material já publicado sobre o assunto, por meio de livros, artigos, dissertações e teses. Na pesquisa documental utilizou-se as normas ASTM E384-17 e ABNT NBR ISO 6892-1:2013 (Errata 2:2018), pois é o tipo de pesquisa que se destaca no momento em que se pode organizar informações, conferindo-lhe uma nova importância como fonte de consulta. A pesquisa laboratorial teve o objetivo de demonstrar como e por que determinado fato é produzido e caracteriza-se por manipular diretamente as variáveis relacionadas com o objeto de estudo. É, ainda, caracterizada como pesquisa aplicada, pois procura produzir conhecimentos para aplicação prática dirigidos à solução de problemas específicos. (PRODANOV; FREITAS, 2013).

\subsection{Materiais e métodos}

O material utilizado é o aço inoxidável duplex, fornecido pela empresa Engenharia e Materiais LTDA (ENGEMASA), na forma de barras cilíndricas, com aproximadamente $25 \mathrm{~mm}$ de diâmetro e $250 \mathrm{~mm}$ de comprimento. A análise química foi feita utilizando um 


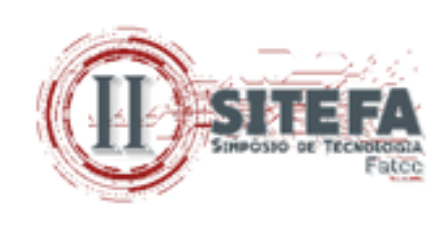

espectrômetro de massas - Marca Termo Scientific- modelo LTQ. O ensaio foi realizado na Universidade de São Paulo, no Instituto de Química de São Carlos.

Os dois corpos de prova foram confeccionados a partir das barras cilíndricas que foram submetidas ao processo de torneamento cilíndrico, utilizando o torno mecânico da marca ROMI, modelo Tormax 20, do laboratório de máquinas operatrizes da Universidade Paulista (UNIP) de Ribeirão Preto/SP.

Durante o processo de torneamento cilíndrico houve uma grande preocupação com o aquecimento do material para que não alterasse sua microestrutura, sendo assim, utilizou-se a menor velocidade disponível no torno e uma grande refrigeração com óleo solúvel. A finalidade deste processo é retirar os óxidos presentes na superfície do material. Em seguida os corpos de prova foram preparados conforme o tipo de análise necessária. Para os processos de soldagem os corpos de prova foram cortados com a espessura de $5 \mathrm{~mm}$ utilizando o processo de sangramento radial no mesmo torno do processo anterior e tomando os mesmos cuidados com o aquecimento. Posteriormente, os corpos de prova foram cortados ao meio, em seu sentido axial para facilitar o processo de confecção das amostras e das juntas de soldagem. O processo de lixamento foi utilizado para a fabricação das juntas de soldagem. Elas foram concebidas nos dois lados dos corpos de prova com o ângulo de aproximadamente $45^{\circ}$.

\subsection{Processos de soldagem}

Os processos de soldagem aplicados aos corpos de prova de aço inox foram o Eletrodo Revestido, MIG e TIG, ambos do Departamento de Engenharia de Materiais da Escola de Engenharia de São Carlos (EESC-USP). Os corpos de prova foram soldados com junta de topo e os cordões de solda foram feitos através de um único passe com a espessura de aproximadamente $2 \mathrm{~mm}$.

O processo de soldagem a arco elétrico com eletrodo revestido foi realizado utilizando o eletrodo AWS E 309 L - 10 com os parâmetros de soldagem: 65,9 Volts e 52 Amperes. A máquina de solda utilizada no processo é da marca CASTOLIN EUTECTIC, modelo DPT $350 \mathrm{HD}$,

No processo de soldagem MIG o eletrodo foi realizado com o uso do AWS A5.9 ER308 LSi juntamente com o gás de proteção, cuja composição química é $75 \%$ argônio e 25\% dióxido de carbono. Os parâmetros de soldagem empregados foram: 26,8 Volts e 116 Amperes. A máquina de solda utilizada no processo é da marca CASTOLIN EUTECTIC, modelo ARCWELD 400S.

O processo de soldagem TIG foi realizado com a utilização do metal de adição AWS A5.9 ER308 LSi, sendo a proteção gasosa feita com argônio industrial. A corrente elétrica empregada durante a soldagem foi 90 Amperes. A máquina de solda utilizada no processo foi a mesma do processo de soldagem a arco elétrico com eletrodo revestido.

$\mathrm{O}$ tratamento térmico foi realizado em forno pré-aquecido a temperatura de $475^{\circ} \mathrm{C}$ durante o tempo de 1 hora e posteriormente os corpos de prova foram resfriados em água a temperatura ambiente". O tratamento térmico foi realizado com o Forno do tipo Mufla digital com temperatura máxima de $1200^{\circ} \mathrm{C}$, da marca QUIMIS, do laboratório de metalografia da Universidade Paulista (UNIP) de Ribeirão Preto/SP. 


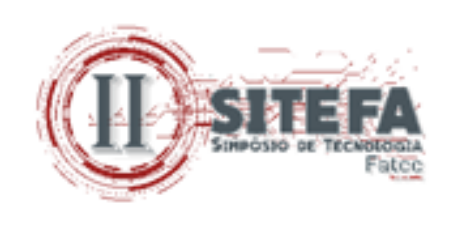

\subsection{Análise microestrutural}

Após os corpos de prova terem passados pelos seus respectivos processos de soldagem e tratamento térmico, foram embutidos com baquelite a quente e lixados e polidos em alumina de $1 \mu \mathrm{m}$. Em seguida, as amostras foram colocadas no ultrassom por 5 minutos. Para a revelação das fases pertencentes a microestrutura foi utilizada o reativo de Behara. A caracterização microestrutural foi realizada através de microscópio óptico da marca AXIO, com registro fotográfico via computador e ampliação de até 1000x, do Departamento de Engenharia de Materiais da EESC-USP. Também foram feitas imagens com a ampliação de 200 vezes em lente objetiva de cada região de soldagem em particular: zona fundida, zona termicamente afetada e metal de base.

\subsection{Ensaios}

A análise da microdureza Vickers nos corpos de prova foram realizadas de forma que o processo de medição começasse na zona fundida, passasse pela zona termicamente afetada e entrasse no metal de base. Foi utilizada uma carga de $0,3 \mathrm{Kg}$ durante o tempo de 15 segundos e dado um espaçamento entre cada impressão do ensaio de $0,25 \mathrm{~mm}$. Os ensaios de dureza foram realizados de acordo com a norma ASTM E384-17 "Standard test methods for microhardness of materials. O microdurômetro utilizado é da marca LEICA, modelo VMHT MOT, existente no laboratório do Departamento de Engenharia de Materiais da EESC-USP. Os resultados das medições foram plotados em gráficos, para que se possa identificar as variações de microdureza.

O ensaio de tração foi realizado segundo a norma ABNT NBR ISO 6892-1:2013 com velocidade de ensaio de $1 \mathrm{~mm}$ por minuto. A máquina utilizada no ensaio é da marca TIMEGROUP, modelo WDW100EB, com capacidade máxima de 100KN, da Faculdade de Tecnologia de Sertãozinho (FATEC).

\section{RESULTADOS E DISCUSSÃO}

Os resultados da análise química do AID obtidos por Espectroscopia de Massa estão apresentados na Tabela 1 mostrando resultado padrão esperado para o aço inox. Os resultados mostram que se trata de um aço inoxidável duplex de classe mais econômica. Isso foi possível graças à ausência de Mo na composição química do aço em estudo. Essa classe de aço pode substituir os graus austeniticos dos aços AISI 304 e AISI 316. (WELLS, 1952). Possui, também, elevado teor de $\mathrm{Cr}$, o que estabiliza o PRE e diminui a tenacidade do material, sendo o principal elemento para a resistência a corrosão.

Tabela 1 - Composição química (porcentagens em peso) para o AID obtida por Espectroscopia de Massa

\begin{tabular}{cc}
\hline Elemento & Composição (\%) \\
\hline $\mathrm{Fe}$ & 67,81 \\
$\mathrm{Cr}$ & 24,9 \\
$\mathrm{Ni}$ & 5,71 \\
$\mathrm{Mn}$ & 0,68 \\
$\mathrm{Si}$ & 0,83 \\
$\mathrm{C}$ & 0,051 \\
$\mathrm{P}$ & 0,022 \\
$\mathrm{~S}$ & 0,002 \\
\hline
\end{tabular}

Fonte: elaborada pelos autores (2019) 


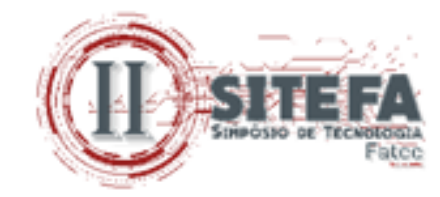

A caracterização microestrutural das amostras de todos os processos de soldagem estão apresentadas na Figura 1, que mostra as imagens do processo de soldagem a arco elétrico com eletrodo revestido não tratado.

Figura 1 - Microestruturas das amostras soldadas pelo processo a arco elétrico com eletrodo revestido

Figura 1a - Panorâmica do Cordão de Solda/ Metal base (50x objetiva)

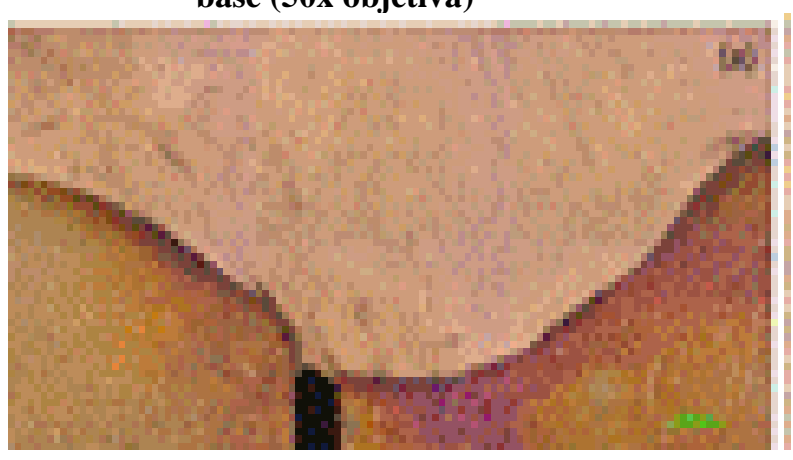

Figura 1c - Zona Termicamente Afetada (200x objetiva)

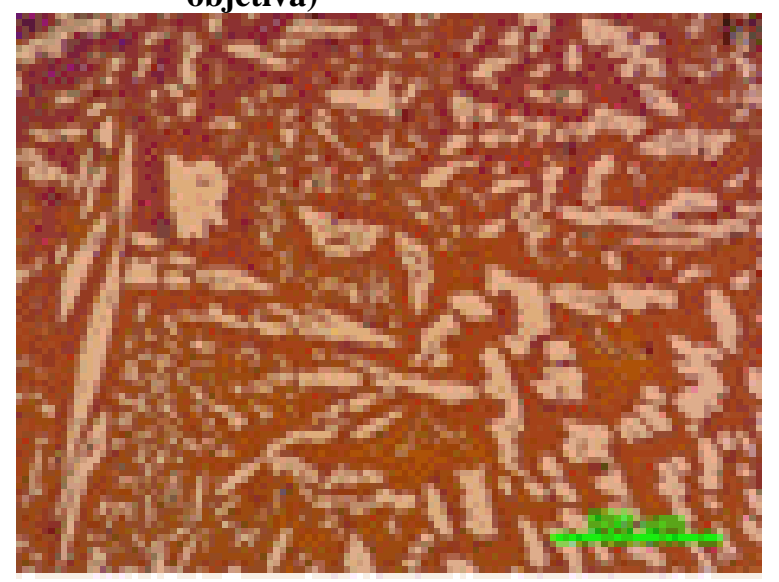

Figura 1b - Zona de difusão (200x objetiva)

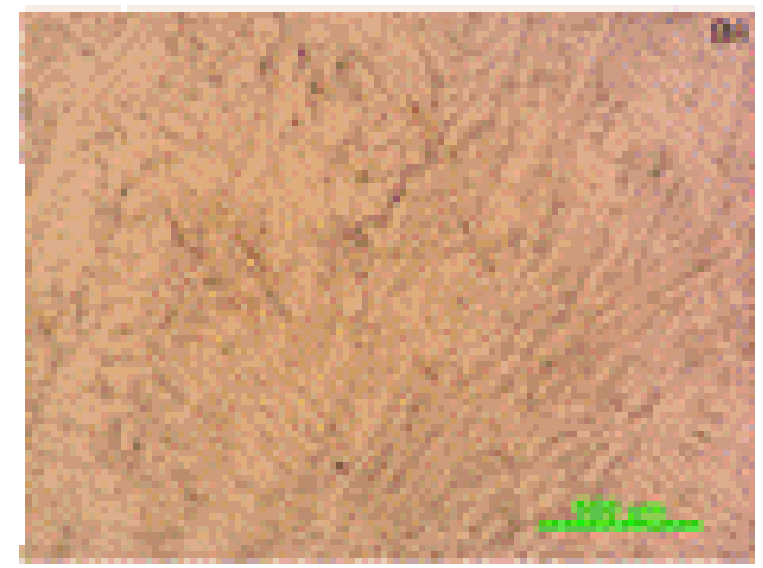

Figura 1d - Metal Base (200x objetiva). Ataque: Behara modificado

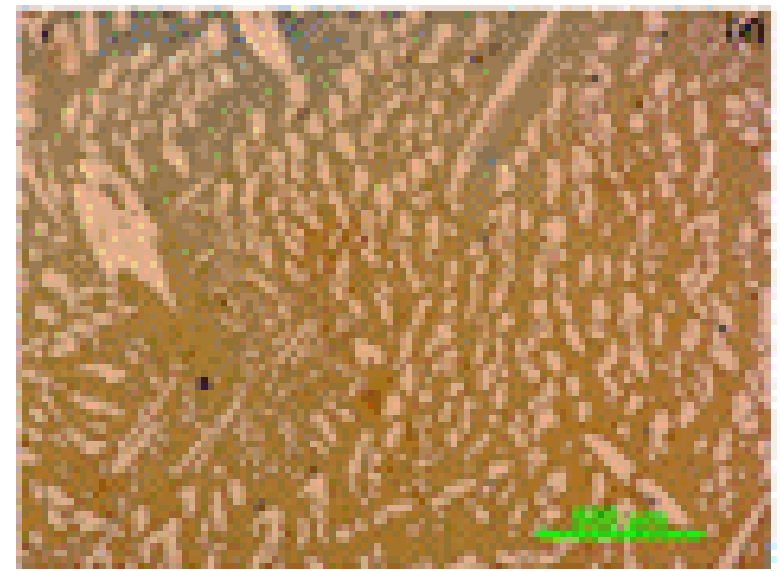

Fonte: imagens emitidas durante a realização da pesquisa (2019)

A Figura 2 mostra as imagens do processo de soldagem a arco elétrico com eletrodo revestido tratado termicamente. 


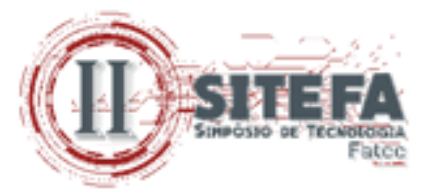

Figura 2 - Microestrutura da amostra soldada pelo processo a arco elétrico com eletrodo revestido tratado termicamente.

Figura 2a -Panorâmica do Cordão de Solda/ Metal base (50x objetiva)
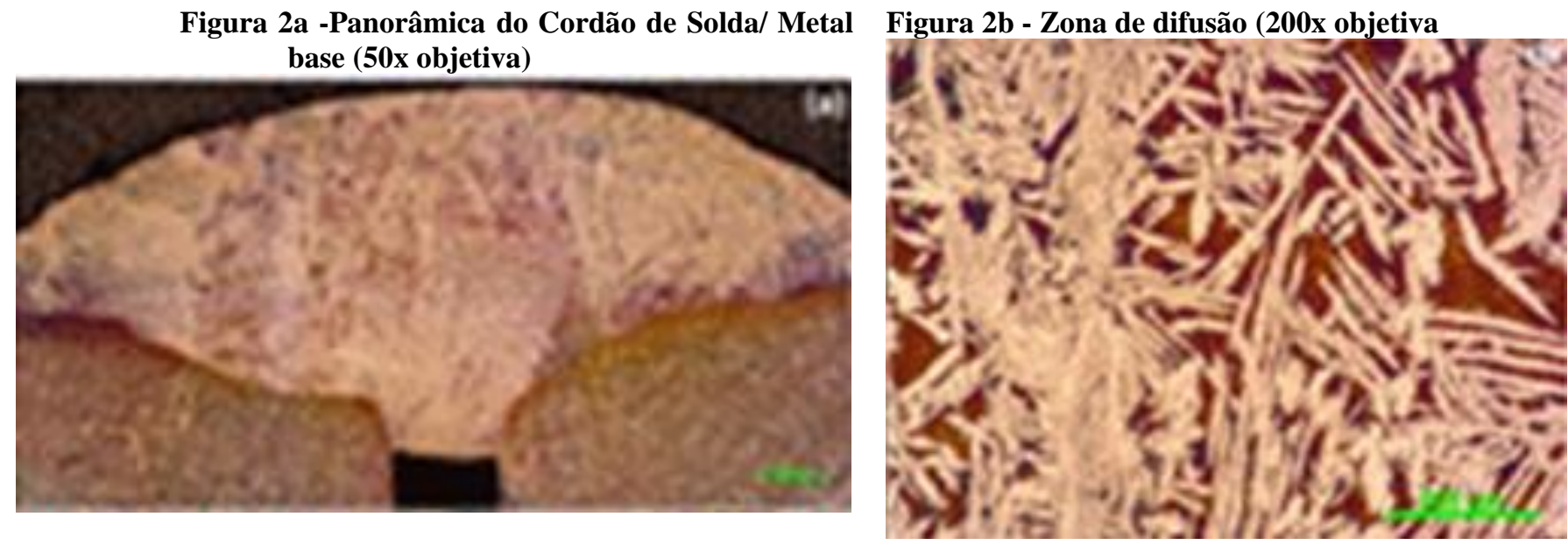

Figura 2c - Zona Termicamente Afetada

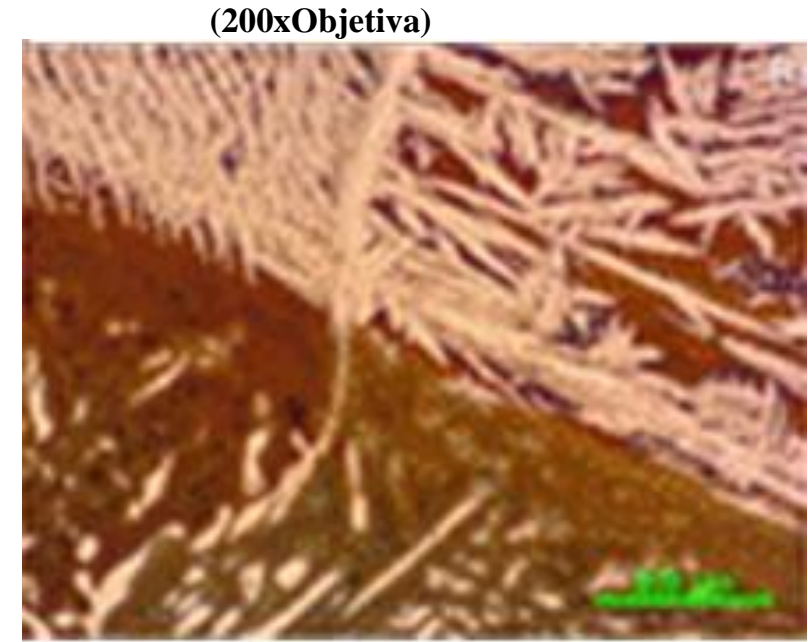

Figura 2d - Metal Base (200x objetiva). Ataque: Behara modificado

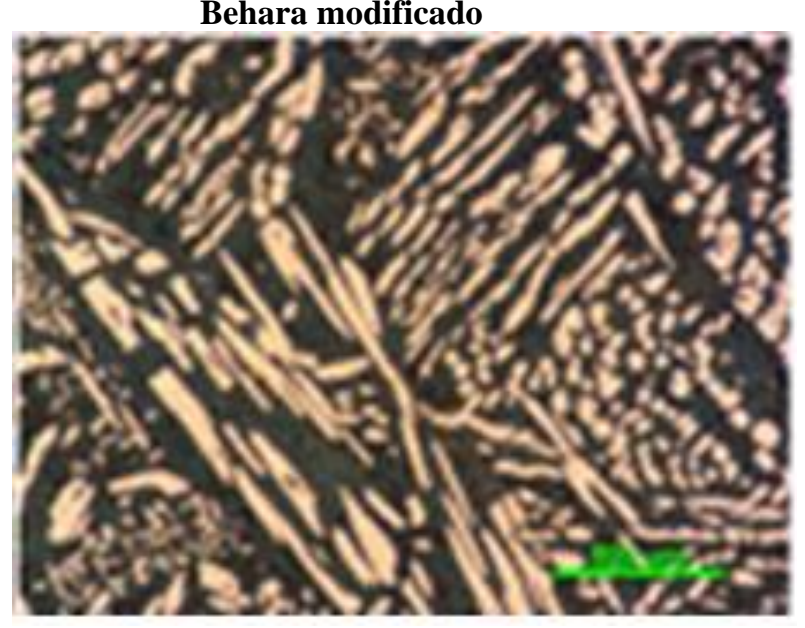

Fonte: imagens emitidas durante a realização da pesquisa (2019)

As Figura 3 e 4 tratam das imagens microestruturais referentes ao processo de soldagem MIG no corpo de prova do AID. A Figura 3 apresenta a microestrutura do corpo de prova do AID sem tratamento térmico enquanto a Figura 4 mostra a microestrutura dele após tratado termicamente. 


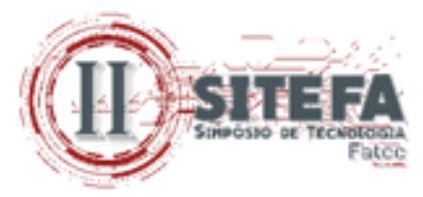

Figura 3 - Microestrutura da amostra soldada pelo processo MIG, não tratado.

Figura 3a - Panorâmica do Cordão de Solda/ Metal base (50x objetiva)
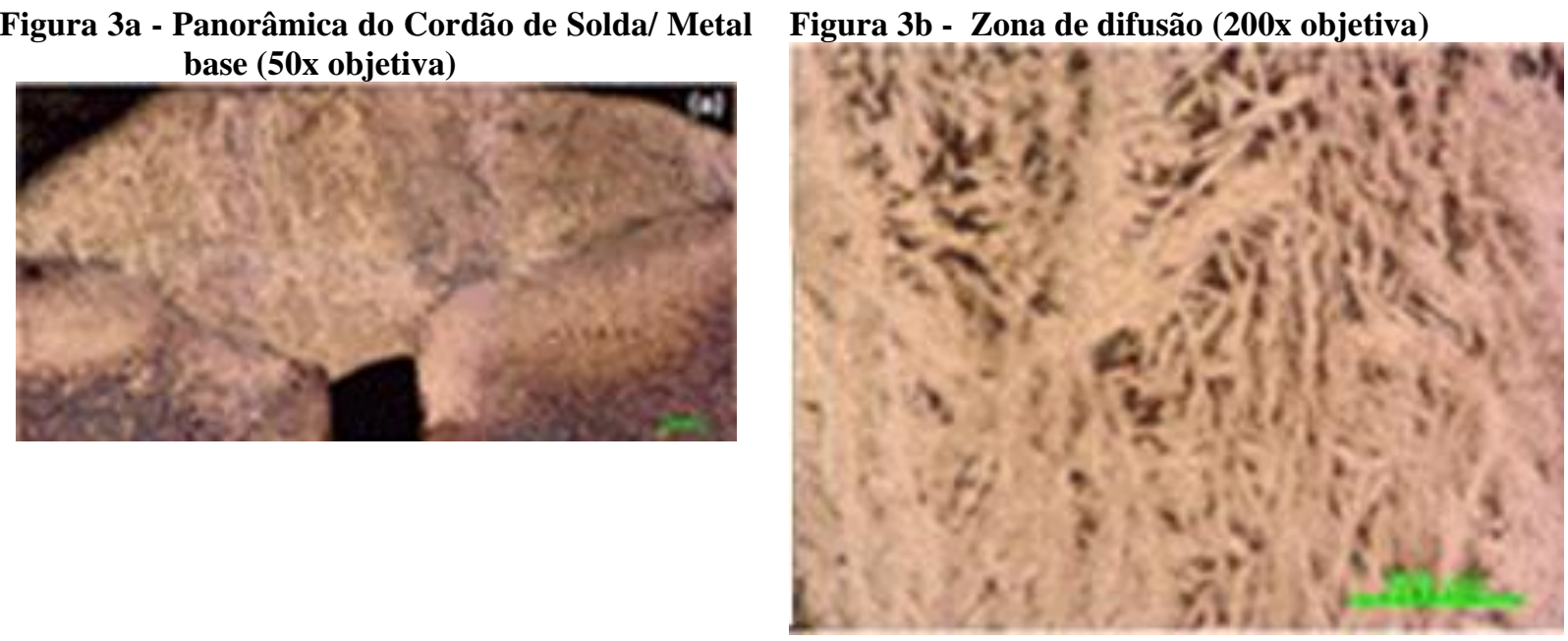

Figura 3c- Zona Termicamente Afetada (200x Figura 3d - Metal Base (200x objetiva). Ataque: objetiva) Behara modificado.

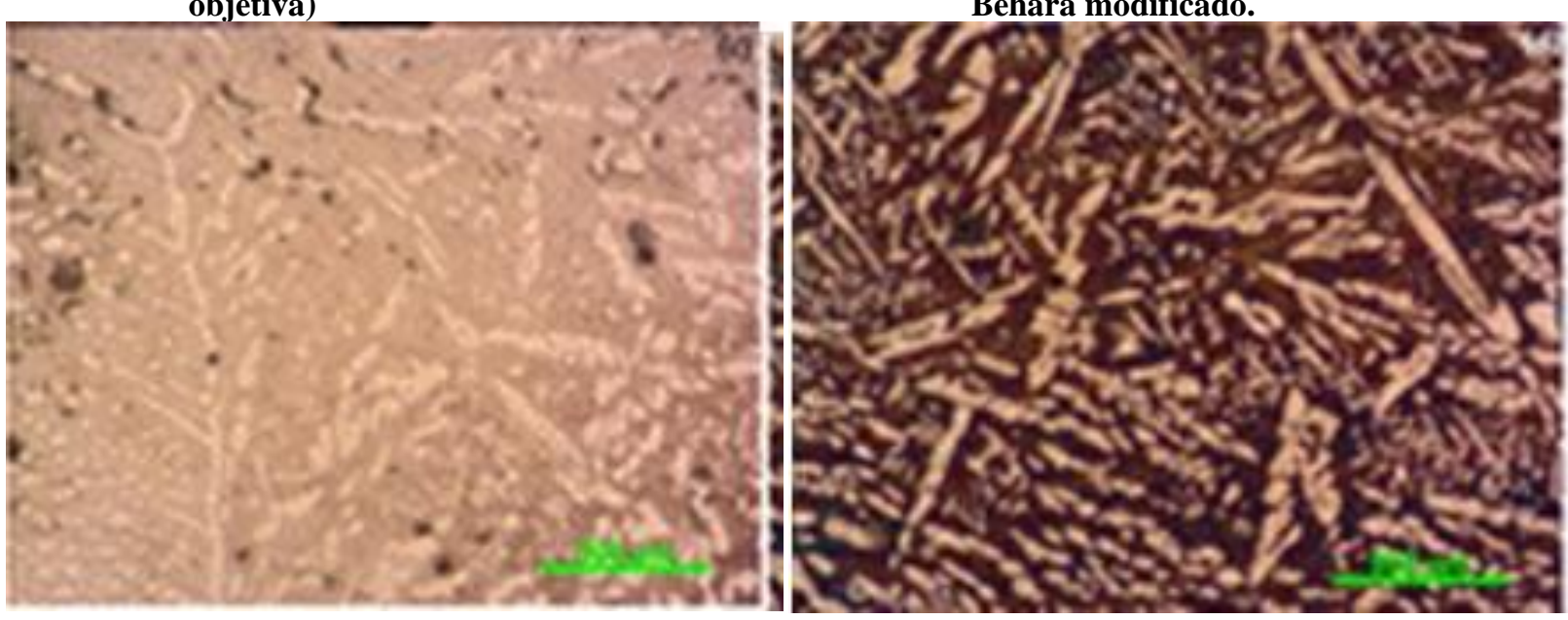

Fonte: imagens emitidas durante a realização da pesquisa (2019) 


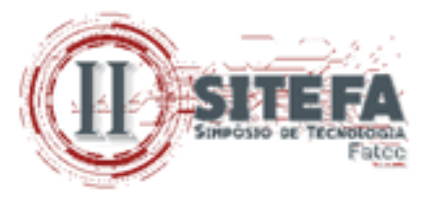

Figura 4 - Microestrutura da amostra soldada pelo processo MIG, tratado termicamente.

Figura 4a - Panorâmica do Cordão de Figura 4b - Zona de difusão (200x objetiva) Solda/Metal base (50x objetiva)
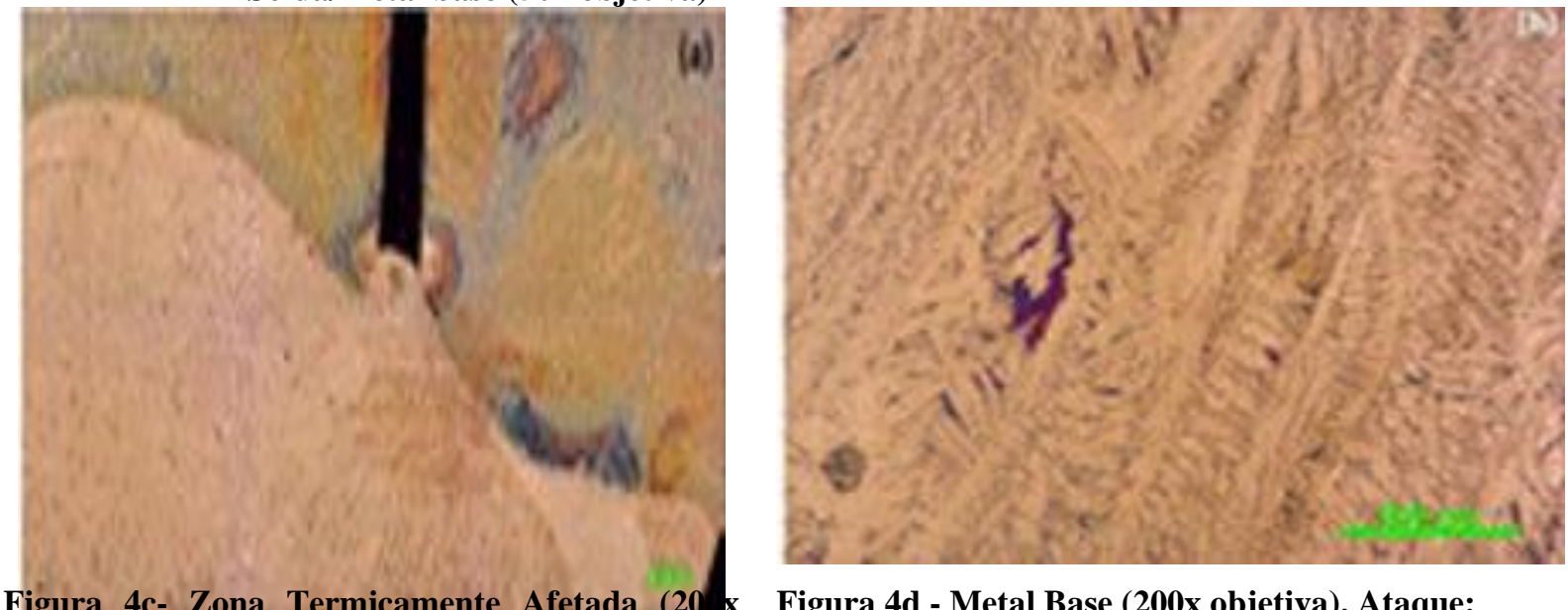

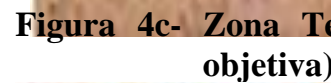

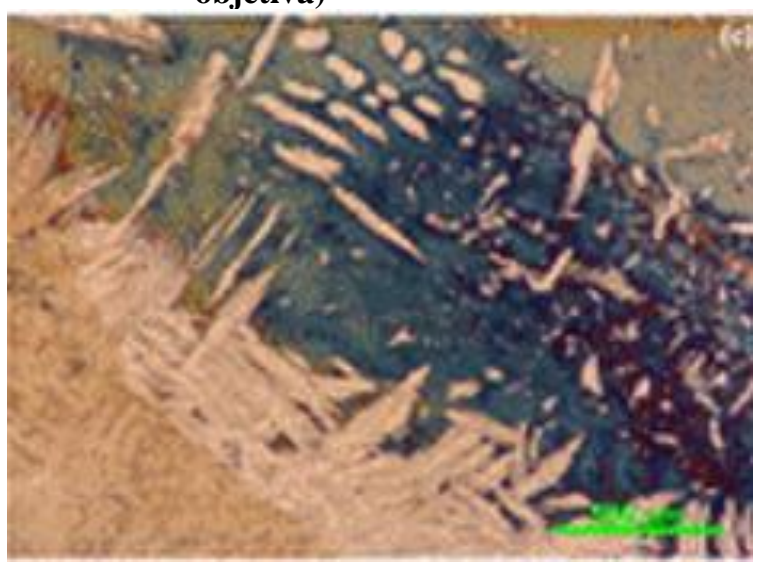

Figura 4d - Metal Base (200x objetiva). Ataque: Behara modificado.

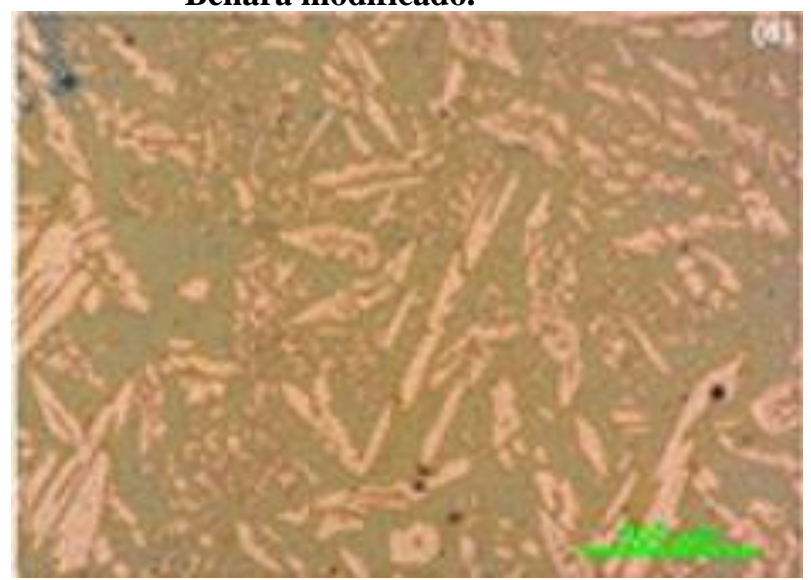

Fonte: imagens emitidas durante a realização da pesquisa (2019)

A Figura 5 apresentadas as imagens do processo de soldagem TIG no corpo de prova do AID não tratado termicamente e a Figura 6 mostra as imagens microestruturais após o processo de soldagem TIG tratado termicamente. 


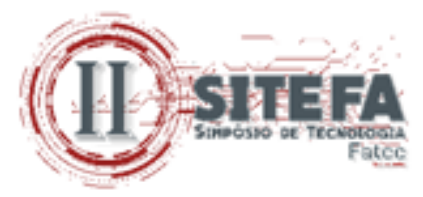

Figura 5 - Microestrutura da amostra soldada pelo processo TIG, não tratado.

Figura 5a - Panorâmica do Cordão de Solda/ Metal base (50x objetiva)

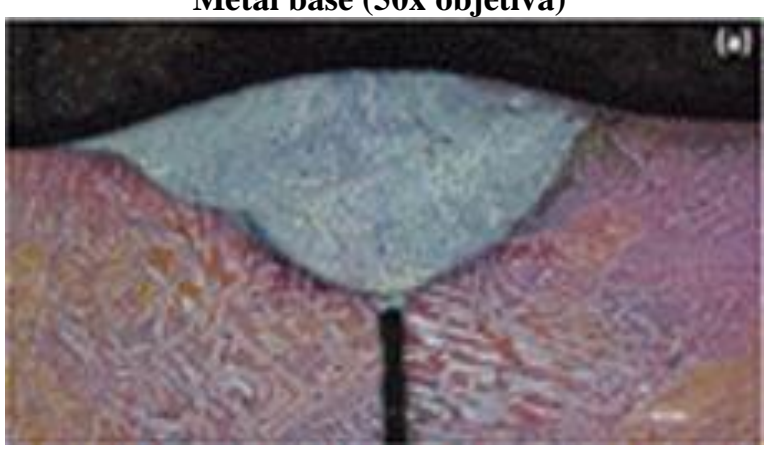

Figura 5c- Zona Termicamente Afetada (200x objetiva)

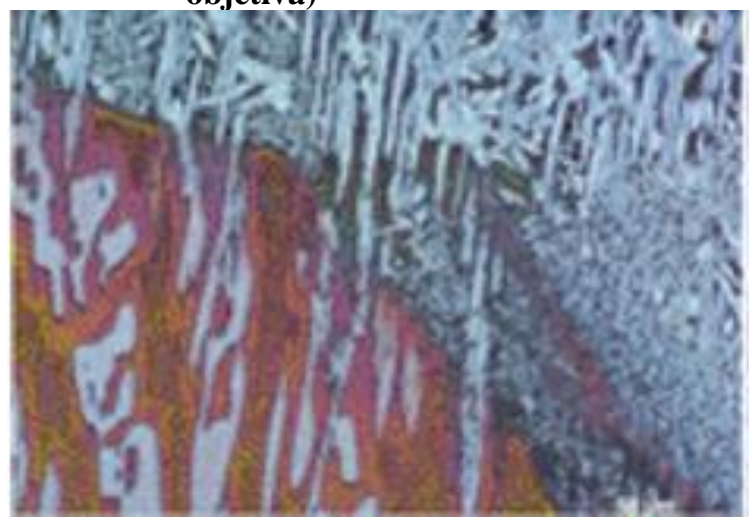

Figura 5b - Zona de difusão (200x objetiva)

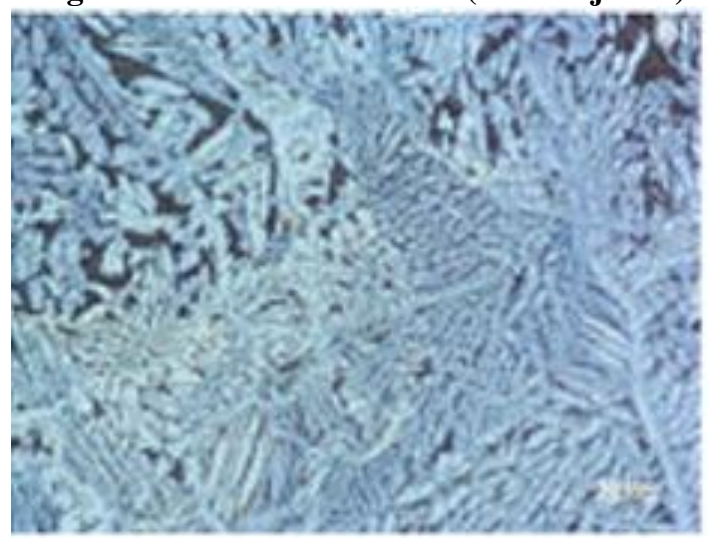

Figura 5d - Metal Base (200x objetiva). Ataque: Behara modificado

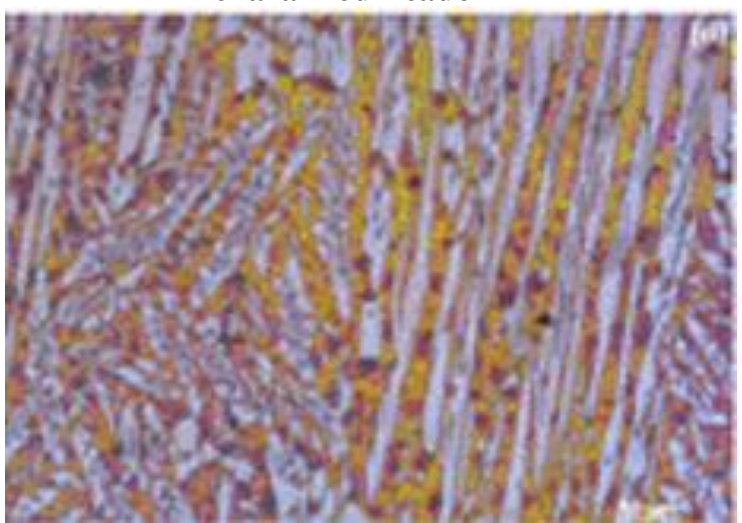

Fonte: imagens emitidas durante a realização da pesquisa (2019) 


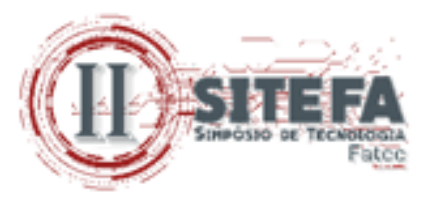

Figura 6 - Microestrutura da amostra soldada pelo processo TIG tratado termicamente.

Figura 6a - Panorâmica do Cordão de Solda/ Metal base (50x objetiva)

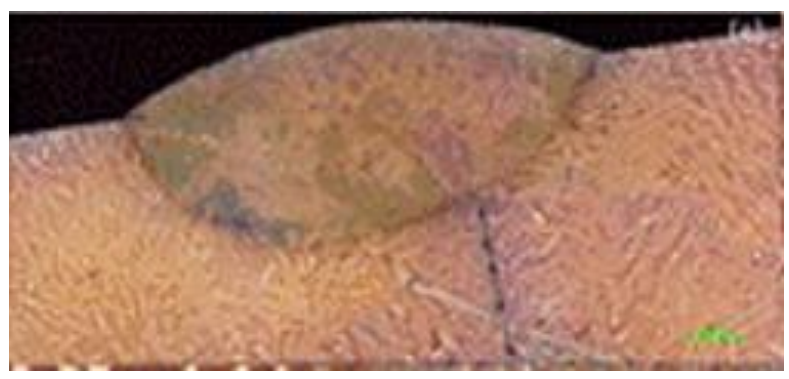

Figura 6c - Zona Termicamente Afetada (200x objetiva)
Figura 6b - Zona de difusão (200x objetiva)

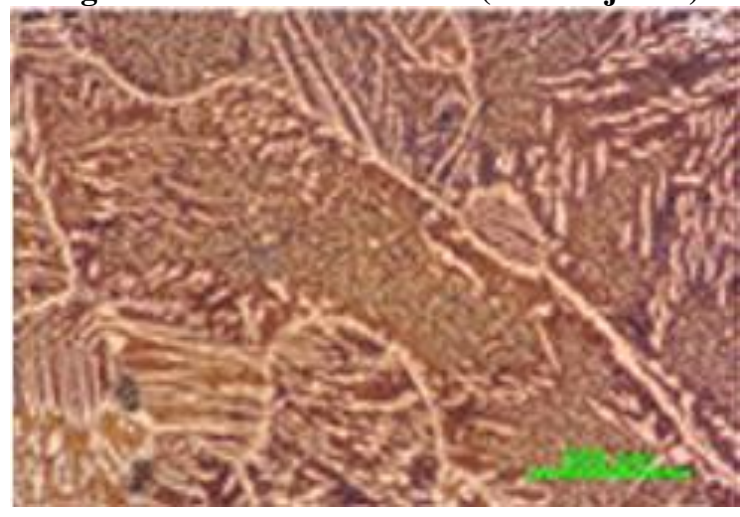

Figura 6d - Metal Base (200x objetiva).Ataque: Behara modificado

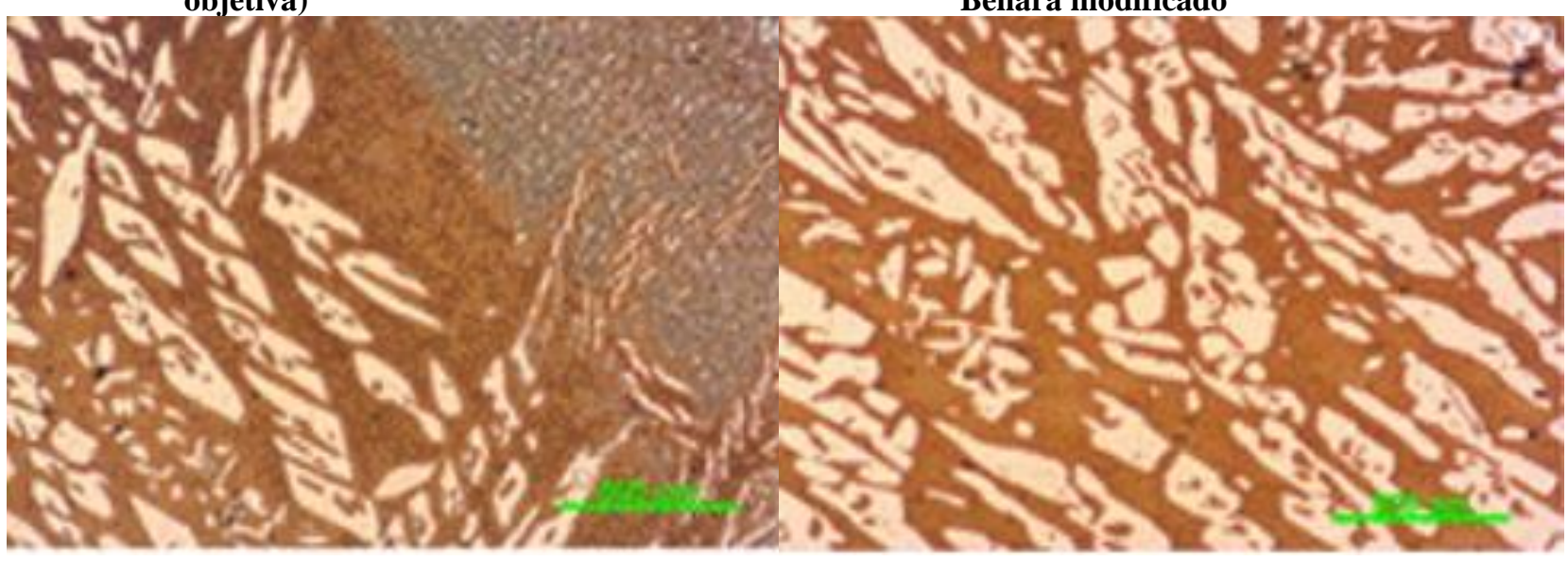

Fonte: imagens emitidas durante a realização da pesquisa (2019)

A caracterização microestrutural tornou possível analisar os defeitos apresentados nas zonas fundidas, zonas termicamente afetadas e metal base de todos os cordões de solda, tal como apresenta a literatura (BRACARENSE, 2000; CALLISTER, 2014). Em todas as amostras houve falta de fusão e penetração do cordão de solda, devido aos parâmetros utilizados nos processos de soldagem. Também foi constatada a presença de poros em todas as amostras, porém não é possível correlacionar sua causa diretamente com os processos de soldagem, pois existe uma quantidade relativa de poros no metal base, possivelmente gerados na manufatura do material. Em ambos os processos de soldagem não ocorreu a presença de trincas, mordeduras e sobreposição.

Diferentes tamanhos de grãos podem ser observados nos cordões de solda e no metal base das amostras. Isso ocorreu devido a composição química do metal de adição ser diferente do metal base, porém, mesmo a composição sendo diferente é o que indicam as normas de soldagem. Através das microestruturas foi possível observar que o processo TIG apresenta uma microestrutura mais homogênea, sendo então, o processo que melhor se sobressaiu, porém, a escolha do processo de soldagem depende da aplicação da junta soldada mostrando resultados coerentes com o que apresenta a literatura (BORSATO, 2001). 


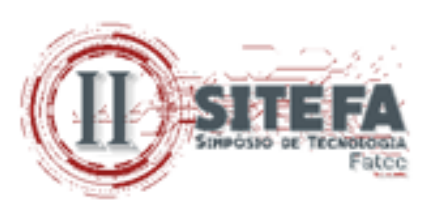

Os ensaios de microdureza Vickers foram realizados com o objetivo de detectar possíveis variações de dureza decorrentes do processo de soldagem e tratamento térmico e foram realizados partindo-se do centro do cordão de solda até alcançar o metal base. A Tabela 2 mostra os valores médios obtidos no ensaio de microdureza Vickers, para todos os processos na condição de não tratados e tratados termicamente. É possível observar na Tabela 2, que no processo de soldagem com eletrodo revestido houve um aumento de dureza significativo, subindo de 183 para 238. Isso foi notado no processo de soldagem MIG, porém a diferença é menos expressiva, sendo que o valor subiu de 253 para 295. Esse aumento de dureza ocorreu devido ao surgimento da fase $\alpha$ ' durante os processos de soldagem. O contrário foi observado no processo de soldagem TIG, uma vez que a dureza média diminuiu de 272 para 267, porém o valor da redução é insignificante, mostrando que não aconteceu nenhuma mudança de fase no processo.

Tabela 1 - Valores médios obtidos no ensaio de microdureza Vickers para cada processo de soldagem na condição de não tratados e tratados termicamente.

\begin{tabular}{ccc}
\hline Processos de Soldagem & Não tratados $($ HV 0,3) & Tratados termicamente (HV 0,3) \\
\hline Eletrodo Revestido & 183 & 238 \\
MIG & 253 & 295 \\
TIG & 272 & 267 \\
\hline
\end{tabular}

Fonte: elaborada pelos autores (2019)

O ensaio de tração foi realizado com o intuito de verificar se houve mudanças no limite de escoamento e tensão de resistência nos corpos de prova após o processo de tratamento térmico de precipitação por envelhecimento. A Tabela 3 mostra os resultados obtidos no ensaio de tração com os corpos de prova não tratados e tratados termicamente. Verificou-se um aumento significativo do limite de escoamento, bem como da tensão de resistência do material após o processo de tratamento térmico de precipitação por envelhecimento; esse aumento foi provocado devido ao surgimento da fase $\alpha$, que aumenta a dureza do material e, consequentemente, sua resistência mecânica.

Tabela 0 - Resultados obtidos no ensaio de tração

\begin{tabular}{cccc}
\hline Corpos de Prova & $\begin{array}{c}\text { Limite de Escoamento } \\
(\mathbf{M P a})\end{array}$ & $\begin{array}{c}\text { Tensão de Resistência } \\
(\mathbf{M P a})\end{array}$ & Força Máxima (KN) \\
\hline \multicolumn{4}{c}{ Corpos de prova não tratados } \\
\hline 1 & 608,69 & 765,98 & 21,66 \\
2 & 667,41 & 769,28 & 21,75 \\
\hline Média & 638,05 & 767,63 & 21,71 \\
\hline 1 & Corpos de prova tratados termicamente & 23,62 \\
2 & 689,96 & 863,9 & 22,72 \\
\hline Média & 640,22 & 790,31 & 23,17 \\
\hline
\end{tabular}

Fonte: elaborada pelos autores (2019)

\section{CONCLUSÕES}

$\mathrm{Na}$ espectroscopia de massa foi possível verificar que o material estudado se trata de um aço inoxidável duplex de classe mais econômica, que pode substituir os graus austeniticos 


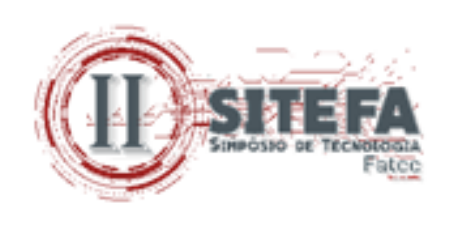

dos aços AISI 304 e AISI 316. Em ambos os processos de soldagem não ocorreu a presença de trincas, mordeduras e sobreposição. Foi possível observar que o processo TIG apresenta uma microestrutura mais homogênea, sendo então o processo que melhor se sobressaiu. $\mathrm{O}$ aumento de dureza detectados nas amostras soldadas e o aumento de resistência mecânica ocorrido no ensaio de tração deve-se ao surgimento da fase $\alpha^{\prime}$ durante os processos de soldagem e tratamento térmico.

Os processos de soldagem se mostraram eficientes e podem ser utilizados na manutenção de equipamentos utilizados pelas indústrias sucroalcooleiras e de extração de petróleo. Pode-se também, futuramente, realizar estudos voltados para a investigação de cada microestrutura presente nos cordões de solda dos processos de soldagem descritos neste trabalho.

\section{REFERÊNCIAS}

ASSOCIAÇÃO BRASILEIRA DE NORMAS TÉCNICAS (ABNT). NBR ISO 6892-1: Ensaio de Tração. Rio de Janeiro: ABNT, 2013.

ASTM. Standard Test Method for Microhardness of Materials. ASTM E384, 1989.

ALBUQUERQUE, V. H. C.; SILVA, E. M.; LEITE, J. P.; MOURA, E. P.; FREITAS, V. L. A.; TAVARES, J. M. R. S. Spinodal decomposition mechanism study on the duplex stainless steel UNS S31803 using ultrasonic speed measurements. Materials and Design Elsevier. v.31, p. 2147-2150, 2010.

ASSOCIAÇÃO BRASILEIRA DO AÇO INOX (ABINOX). Coletânea de Informações Técnicas-Aço Inoxidável. Disponível em:

http://www.abinox.org.brupfilesarquivosbibliotecatipos-de-acos-inoxidaveis.pdf . Acesso em: 3 out. 2016.

BORSATO, K. S. Caracterização microestrutural e de propriedades mecânicas de chapas espessas de aço inoxidável duplex UNS S31803, submetido a ciclos térmicos de soldagem. Tese de D.Sc., PPGEM/UFSC, Florianópolis, Santa Catarina, Brasil, 2001.

BRACARENSE, A. Q., Processo de Soldagem TIG - GTAW. Belo Horizonte: Editora UFMG, 2000.

CALLISTER, W. D. J., Fundamentos da ciência e engenharia de materiais: uma Abordagem Integrada. 4. Ed. LTC - Livros Técnicos e Científicos Editora Ltda., 2014.

CHARLES, J., Why and Where duplex stainless steel, In: Conference Duplex Stainlesssteels. Proceedings. The Netherlands. p. 29-42, The Netherlands, 1997.

LIMA, D. B. P. L., Avaliação da Soldabilidade do Aço Inoxidável Superduplex UNS

S32750. Dissertação de Mestrado, DEM/UFPR, Curitiba, Paraná, Brasil, 2006. 


\section{(11)}

MAGNABOSCO, R., Magalhães, M. Formação de fase sigma após rápido envelhecimento entre $700 \mathrm{C}$ e $900 \mathrm{C}$ do aço inoxidável dúplex UNS S31803 (SAF 2205). In: $\mathbf{5 9}^{\circ}$ Congresso Internacional Anual da ABM. p. 2758-2767, São Paulo: ABM, 2004.

MARQUES, P.V., MODENESI, P.J., BRACARENSE, A. Q. SOLDAGEM: fundamentos e Tecnologia. Belo Horizonte: Editora UFMG, 2005.

MATEO, A., GIRONES, A., KEICHEL, J., LLANES, L., AKDUT, N., ANGLADA, M., Cyclic deformation behavior of superduplex stainless steels. Materials Science and Engineering A314, p. 176-185, 2001.

NILSSON, J. O. Super Duplex stainless steels. Materials Science and Technology. v. 8, n. 8, p. 685-700, 1992.

PRODANOV, Cleber Cristiano; FREITAS, Ernani Cesar. Metodologia do Trabalho Científico: métodos e técnicas da pesquisa e do trabalho acadêmico. 2. ed. Novo Hamburgo: Feevale, 2013.

SANTOS, F.S. Espectroscopia de Fotoelétrons (Xps) no Estudo de Filmes Passivos sobre Aços Inoxidáveis Envelhecidos em Baixas Temperaturas. Dissertação de Mestrado, DEMa/UFSCar, São Carlos, São Paulo, Brasil, 2008.

SEDRIKS, A. J., Corrosion of stainless steels. 2 ed. New York, John Wiley \& Sons, 1996.

SOLOMON, H. D.; DEVINE JUNIOR, T. M. Duplex Stainless Steels - A tale of two phases, Proceedings Metals Park: ASM, p. 693-756, 1982.

Duplex stainless steels - a tale of two phases. In: Conference Du-plex Stainless Steels Proceedings. p. 693-757, Ohio, 1984.

WAINER, E., BRANDI, S. D., MELLO, F.D.H. Soldagem - Processos e Metalurgia, ABS Editora, 1992.

WELLS, A. A. Heat flow in welding. Welding Journal, v. 31, n. 5, pp. 263-267, 1952. 